\title{
CÁDIZ Y EL TRÁFICO DE ESCLAVOS: DE LA LEGALIDAD A LA CLANDESTINIDAD
}

Martín Rodrigo y Alharilla y María del Carmen Cózar Navarro (eds.), Madrid, Silex Universidad, 2018, 321pp.

Este bienvenido libro sobre Cádiz, el último gran puerto esclavista europeo del siglo XIX, nace de una investigación colectiva denominada «La participación española en el tráfico de esclavos y los legados de la esclavitud en España, 1765-1886.» Este volumen presenta diez intervenciones sobre la historia comercial, política, económica, diplomática, social y de desarrollo de los saberes vinculados a la trata gaditana. Salvo por el capítulo de Arturo Morgado García y el de José Piqueras y Emma Vidal, el resto de las intervenciones está centrada en el siglo XIX y en particular en las dinámicas impuestas por la clandestinidad de este tráfico luego de 1817. No está demás mencionar que se podría hacer un volumen colectivo similar sobre la trata inicial a través de Cádiz durante los siglos XVI y XVII, teniendo en cuenta la historia de este puerto y su relación con Portugal, las islas Atlánticas africanas (Canarias y Cabo Verde, entre otras), así como con América. Este tema, por supuesto, está más allá de la investigación de los editores y autores de este libro colectivo, por lo que aquí no se critica su falta, sino que se alienta a su futura inclusión en otros volúmenes.

La introducción señala que Cádiz fue el más importante puerto esclavista europeo luego de 1817, cuando ya los grandes puertos esclavistas ingleses y franceses habían dejado casi completamente de participar en esta actividad. Cádiz surgió como uno de los pocos puertos del Viejo Mundo en donde todavía se organizaban viajes esclavistas hacia las Américas en tiempos de la clandestinidad impuesta por el tratado anglo-español contra la trata. Esta es una historia atlántica en su mejor perfil en tanto interroga, desde varias perspectivas, las relaciones de Cádiz con el resto de la España peninsular, con Cuba y Santo Domingo, y con los puertos africanos vinculados a estas redes comerciales.

El capítulo de Morgado García ofrece un excelente análisis basado en protocolos y libros de bautismo, sobre los esclavos que vivían en Cádiz en el siglo posterior a 1650 . Ambas fuentes muestran que sólo la mitad de estos esclavos tenían su origen en el África subsahariana, y que había minorías significativas de personas esclavizadas registradas como «berberiscos,» «blancos,» «moros,» «membrillos» y «turcos». Por lo tanto, no es 
extraño encontrar en los puertos americanos esclavos de este origen (ibérico, turco y norafricano), que luego de una travesía gaditana, se quedaban en el Nuevo Mundo. No obstante, a medida que nos acercamos a la mitad del siglo XVIII, los porcentajes y cantidades absolutas de estas personas casi desaparecen. Los esclavos norafricanos llegaban a Cádiz, entre otras razones, por las actividades corsarias españolas en el Mediterráneo, mientras que los turcos venían como resultado de las guerras con el Imperio Otomano en los Balcanes y otras regiones durante el siglo XVII. Paradójicamente, las fuentes ofrecen datos menos específicos sobre los orígenes de los esclavos venidos del Mediterráneo que de los africanos sub-saharianos. En este último caso, las zonas de origen más relevantes fueron Congo, Angola, Loango, y Cabo Verde, entre otras, lo cual señala una clara preponderancia de rutas esclavistas de África Centro-Occidental bajo control portugués o dominadas por el comercio holandeses (Loango). A estos hay que sumarles personas esclavizadas nacidas en Portugal y en las colonias españolas americanas para tener una imagen comprehensiva de la muy diversa población esclava de Cádiz en este período.

Eloy Martín Corrales intenta consolidar los diferentes estudios de caso sobre la esclavitud en España durante el siglo XIX, hasta la fecha misma de su abolición en 1837. A partir de los tratados entre las autoridades norafricanas y España durante el siglo XVIII, se tornó extraño el arribo de esclavos provenientes del Mediterráneo, proviniendo los esclavos a partir de 1791 casi exclusivamente del África Sub-sahariana. El autor señala a Cádiz como la ciudad de mayor población esclava en la España peninsular durante los años previos a la abolición. Asimismo, da cuenta de los debates cotidianos en Cádiz, así como en otras ciudades españolas, sobre la supervivencia de la esclavitud a nivel local en lo relacionado al trato dado a los esclavos por los amos, sobre las lealtades políticas de los últimos, y sobre cómo la persistencia de la esclavitud en Cuba dio una segunda vida a la esclavitud en la España peninsular.

En su trabajo, José Piqueras y Emma Vidal señalan la importancia de los comerciantes británicos en la trata hacia Cuba, desde la época del Asiento Inglés emergente de la Guerra de Sucesión hasta la abolición británica de la trata en 1807. Los autores también destacan las dificultades de los traficantes españoles (que vivían en la península) para entrar en este tráfico transatlántico. Cabe señalarse que los comerciantes españoles que vivían en América fueron más exitosos en la trata intra-americana de este período, llevando a cabo viajes esclavistas entre Brasil y el Río de la Plata, Curazao y Venezuela, y desde Jamaica a Cuba. Los autores parecen desconocer este tráfico interno al realizar un compendio de las cifras, y de paso criticar los datos ofrecidos por Voyages: The Transatlantic Slave Trade Database, que solo ofrece datos de viajes esclavistas transatlánticos como su nombre lo indica, y no intra-americanos. En otras palabras, la diferencia entre los datos sobre Cuba que se encuentran en Slave Voyages Database y las cifras totales de arribos está constituida, mayormente, por estos viajes entre islas del Caribe. Esta diferencia va a ser subsanada a partir de publicarse una base de datos de la trata intra-americana en la misma página web $<$ www.slavevoyages.org $>$. Este tráfico intra-caribeño fue tan significativo como el transatlántico para Cuba en los años 1790s y durante la primera década del siglo XIX. 
Los capítulos de Enriqueta Vila Vilar y de José Luis Belmonte Postigo se centran en la discusión sobre la esclavitud y su abolición en las Cortes de Cádiz y los efectos de la segunda proclamación de la Constitución de Cádiz en Santo Domingo. Mientras que la primera analiza diferentes exposiciones, como las de Antillón, Argüelles y otros, el segundo se centra en la complicada política de Santo Domingo entre 1790 y 1820. Belmonte Postigo brinda un análisis de la difícil recepción del liberalismo gaditano por las clases populares dominicanas, y de los vaivenes del independentismo conectado con el problema de la esclavitud. Y por supuesto, para el caso dominicano, las idas y venidas sobre independencia y abolición se vinculaban estrechamente a la política de Haití. Más allá de la esclavitud se encontraba la cuestión sobre el grado de extensión de derechos para los dominicanos de ascendencia africana. Este capítulo ofrece ejemplos de cómo se discutía esta cuestión y las prácticas generadas a su alrededor, como la negativa del Arzobispo de Santo Domingo a la orden oficial de anotar en libros separados a los blancos, morenos, y pardos, así como a través de las historias extraordinarias de Pablo Alí y Juan de Santillán en pos de obtener la ciudadanía española.

Los cinco trabajos finales constituyen el centro del libro en lo concerniente a la transición de legalidad hacia la clandestinidad del tráfico en las rutas esclavistas que conectaban Cádiz y Cuba. El capítulo de Lizbeth J. Chaviano Pérez pone en evidencia la centralidad de Cádiz como puerto desde donde se organizaban viajes esclavistas, particularmente luego de 1815. Chaviano Pérez sistematiza los datos del diario Vigía de Cádiz y ofrece nueva información sobre la salida de barcos esclavistas hacia África, así como la llegada de barcos de La Habana que empleaban Cádiz como puerto de avituallamiento para salir a embarcar esclavos. En la medida que Cádiz ofrece datos de partida, es difícil tener certeza sobre el lugar en donde estos navíos embarcaron esclavos con cierta precisión. No obstante, este trabajo ofrece un análisis muy claro y detallado de los circuitos comerciales entre Cádiz y La Habana hacia África, a veces multilaterales justamente para evadir los controles británicos, en lo concerniente a fechas, avituallamiento, y casas comerciales, así como sobre algunas estrategias para evitar la represión británica contra la trata en alta mar. En perfecta consonancia, el capítulo de Martín Rodrigo y Alharilla se centra en la transición hacia la ilegalidad de la trata gaditana, así como su incremento, a partir de utilizar fuentes británicas y españolas. En esta parte, Rodrigo y Alharilla examina las redes comerciales de Jaime Tintó, Pedro Martínez, los hermanos Abarzuza y Antonio Vinent Vives, lo cual expande el estudio de la trata gaditana y expone sus conexiones con Barcelona y las Baleares. Fueron estas casas, asimismo, las que avanzaron en establecer factorías españolas en el Río Gallinas (Sierra Leona) así como en otras regiones de la costa del África Occidental. Este capítulo da cuenta de otras actividades de los tratantes de esclavos, como convertirse en banqueros de Cádiz, lo cual ejemplifica las conexiones invisibles de la trata y su penetración en el tejido social de las elites gaditanas. En este sentido, este es un gran ejemplo sobre las implicaciones de la trata esclavista en los puertos europeos más allá de los perpetradores de este tráfico. El trabajo de María de Carmen Cózar Navarro también corre el velo de un Cádiz oculto, el de la trata esclavista, durante el Reinado de Isabel II, que resulta difícil de investigar debido a las estrategias de los 
comerciantes y financistas en pos de mantenerlo lejos de la mirada pública. Esta es una excelente continuación a los dos capítulos previos, en tanto la autora logra mayor densidad documental al centrarse en la casa de Pedro Martínez \& Cía. Este trabajo analiza la trayectoria comercial de Martínez y su familia, sus traslados entre La Habana y Cádiz, su red de corresponsales a ambos lados del Atlántico, sus negocios en La Habana y Matanzas, así como sus conexiones con otros traficantes españoles y luso-brasileños.

Luego de estos capítulos centrados en Cádiz y sus conexiones atlánticas y mediterráneas, el trabajo de Mercedes García Rodríguez estudia la ilegalidad desde la perspectiva de los desembarcos en Cuba. Para ello, emplea dos estudios de caso de introducciones de esclavos en Pinar del Río. En esta ocasión, fueron autoridades coloniales, comerciantes y empleados de casas de transporte, entre otros, los protagonistas de estas redes capilares de ocultación de arribos esclavistas y reembarco hacia otros puertos. Si bien este artículo no conecta directamente Cuba con Cádiz, permite a los lectores concebir cómo era la operativa de desembarco de las redes de traficantes gaditanos mencionadas en los tres capítulos anteriores. Leida Fernández Prieto también aporta un trabajo sobre la trata hacia Cuba, pero desde la mirada del intercambio de conocimiento sobre plantas y animales a través de las conexiones marítimas de este tráfico. Este trabajo señala los legados etno-botánicos africanos y europeos en Cuba, y en particular, ofrece una mirada sobre la vida material del barco esclavista español. De este modo el barco esclavista además de una prisión flotante, se presenta como un escenario de intercambio de información y saberes entre África, Europa, y las Américas. Hay una historia sobre el barco esclavista español, entendido como objeto de estudio transnacional e interdisciplinario, que en algún momento tendrá que ser escrita, y que este capítulo da pistas de cómo concebir. En esa misma orientación, pero desde el campo literario, se puede mencionar el trabajo de Lisa Surwillo, Monsters by Trade: Slave Traffickers in Modern Spanish Literature and Culture (2014).

En síntesis, este volumen colectivo presenta reflexiones sobre el tráfico de esclavos y su vinculación con el resto del comercio atlántico español, sobre la alta política de la esclavitud y su abolición así como sobre la política cotidiana de quienes intentaban vivir la transición desde la sujeción a la ciudadanía, y fundamentalmente, sobre la importancia de la trata y la esclavitud para Cádiz y su comunidad mercantil. De esta forma, este libro constituye una pieza más en pos de bosquejar en forma más comprensiva el vasto mosaico histórico de la trata y la esclavitud en las Españas.

Alex Borucki

Universidad de California Irvine

(Irvine, CA, EEUU) 